\title{
Las Letras gallegas, los dramaturgos gallegos y los artistas de Galicia en la vida y en la obra de Ricard Salvat (Primera aproximación)
}

\author{
Xesús Alonso Montero \\ Universidad de Santiago \\ Real Academia Gallega \\ Centro de Estudios Rosalianos
}

\section{Palabras iniciales}

Con un poco de retraso redactamos la biografía «gallega» de Ricard Salvat, y lo hacemos de un modo un tanto esquemático, convencidos, en este momento de que en ocasión más propicia abordaremos el tema con más amplitud.

No otra cosa merece de Galicia el hombre de Letras que nos dejaba para siempre el 24 de marzo del presente año. Yo tengo la obligación de realizar ese trabajo, no sólo por mi vieja amistad con él sino por el hecho de que poseo material literario y documental muy útil para acometerlo con minucia (cartas, programas...). Cuando, cuanto antes, amplíe la presente biografía, utilizaré parte del ingente material del archivo de Isaac Díaz Pardo, el artista plástico que más colaboró con Salvat como director teatral y el hombre que, en momentos muy especiales, reconoció y alentó algunas de las actividades del gran ciudadano de la cultura que fue Ricard Salvat.

Para lectores poco informados en la vida y en la obra de nuestro escritor, ofrecemos la columna que le dedica el Nou Diccionari 62 de la literatura catalana (Barcelona, Edicions 62, 2000, pp. 675-76):

Salvat, Ricard (Tortosa, 1934). Dramaturg, assagista, director escènic de teatre i òpera, profesor y promotor cultural. Cursà filosofía i lletres a la Universitat de Barcelona, sociología i filosofía a Heidelberg i ciències teatrals a Colònia. De retorn a Catalunya fundà i dirigí diveross grups teatrals. Després d'una altra estada a Alemanya, l'any 1960 fundà l'Escola d'Art Dramàtic Adrià Gual. És l'introductor del realisme èpic a la península i difusor de l'obra de Brecht (sobre la producción del qual ha dirigit diversos muntatges teatrals) i Piscator. Obtingué un remarcable èxit aplicant els seus coneixements en el muntatge Ronda de mort a Sinera (1965), sobre textos de Salvador Espriu triats i confegits per ell. Com a dramaturg ha escrit les obres següents: Mort d' home (1961), Nord enllà (1962), i Allí on neixis tant se val, estrenada a Tolosa de Llenguadoc l'any 1966. El 1959 guanyà el premi Joanot Martorell amb la novel-la Animals destructors de lleis. Ha traduït al castellà obres de maria Aurèlia Capmany, Salvador Espriu, Max Frish etc., i ha confegit l'espectacle 
Adrián Gual y su época (publicat en català el 1972) per presentar a Madrid l'obra d'aquest autor Misteri de dolor l'any 1966. Ha publicat Teatre contemporani (1966), en dos volums, Els meus muntatges teatrals (1971), o Brecht $i$ Barcelona (1985). També ha col-laborat en l'edició de diversos volums, com les Obres Completes d'Agustí Bartra, Primera historia d'Esther o Antígona de Salvador Espriu, o el Teatre de Shakespeare (1996) preparat per José María Valverde. Ha dirigit diversos muntatges televisius entre els quals destaca En escena: 100 anys de teatre català (1994), i ha organizat les Jornades Bertolt Brecht i diverses exposicions, com 100 anys Brecht al Teatre nacional (199899). L'adaptació de l'obra del dramaturg i poeta alemany A la jungla de les ciutats li ha valgut el Premi Nacional de Teatre de la Generalitat 1999. Ha collaborat en diverses publicacions, entre les quals cal destacar Serra d'Or, Presència, i Primer Acto.

Es una biografía literaria bastante parca, pero expresiva de la intensidad y polifacecia teatral de Salvat en esas cuatro décadas (1960-2000) Este Dicciona$r i$ omite la obra no catalana protagonizada por Salvat, como director teatral, en escenarios tan distintos, entre otros, como Madrid, Roma, México y Budapest. Dentro y fuera de Barcelona, hay grandes autores españoles que están en deuda con nuestro gran director (Valle-Inclán, Rafael Alberti...), y lo mismo podemos decir de importantísimos dramaturgos gallegos (Castelao, Álvaro Cunqueiro). Pero Ricar Salvat no sólo se asomó a las letras gallegas como director teatral y estudioso del teatro sino que tradujo al catalán dos poemarios gallegos muy valiosos (Martín Códax, García Lorca) y unos textos en prosa, de Castelao, muy reveladores. Hay otros acercamientos a las Letras gallegas de que damos cumplida noticia en las presentes páginas.

\section{BIOBIBLIOGRAFÍA GALLEGA DE RICARD SALVAT: ESQUEMA CRONOLÓGICO EN VEINTE «CAPÍTULOS»}

\section{Dos fechas de su «prehistoria»: 1953, 1958}

Fueron sus dos primeros encuentros con Galicia, magníficamente contados en unas deliciosas páginas evocativas de 1975: «Com vaig descubrir la figura de Castelao» ${ }^{1}$. Así refiere el primer viaje:

Hi havia anat, per primer cap, l'estiu del 53. Havia obtingut una beca per a seguir les clases a l'abans esmentada Universitat de Santander i un cap allí vaig aprofitar-ho per arribar-me, amb uns pocs diners que havia estalviat, a les terres de Rosalia, la poetessa, que des molt aviat, des molt nen, jo havia —i continuo encara - admirat tant. Galicia em va produciré una mena de sotsobre, tant que, ja des del primer contacte, em va guanyar per a sempre més (pp. 44-45).

${ }^{1}$ En el vol., que yo coordiné, Homenaxe multinacional a Castelao, Madrid, Akal Editor, colección Arealonguiña, 1976, pp. 44-50. Reproducido en el vol. de R. S. Escrits per al teatre, Institut del Teatre de la Diputació de Barcelona, 1988, pp. 103-106. 
Una buena parte del relato se centra en su viaje de 1958 a la comarca de Betanzos, a un albergue del SEU, para hablar, a jóvenes universitarios en vacaciones, de teatro español. El «curset» fue un desastre: «un pur pretext qué els joves que hi havien anat paguessim banyar-se i divertir-se». Fue entonces cuando, en una sala interior de la vivienda de un tabernero, quedó impresionado por «la figura de Castelao... una figureta o petita escultura colorida que reproduïa un home vestit de negre, fortamente encorbat, més aviat prim i am bulleres». Se trata de la figura hecha en la Cerámica Celta de Cesures que, desde 1950, algunos hogares gallegos guardaban con orgullo. Era un icono semiclandestino, lo que advirtió Salvat en aquella casa cuyo dueño mostró una gran preocupación al saberse descubierto por aquel joven desconocido. Intrigado, le expuso su inquietud, días después, a un amigo coruñés con quien se trasladó a la mencionada taberna cuyo propietario, en esta ocasión, escondía «la figureta», entre trapos, en un armario. Resultó lo que sospechaba el joven coruñés: era la figura de Castelao, del que nada sabía Salvat. La primera noticia se la ofrece el amigo. «Murió, no hace mucho, en Buenos Aires». De él recibe la primera lección:

Tot tornant cap a l'alberg aquell amic meu m'inicià a la figura I personalitat de Castelao. I des d'aleshores jo vaig anar demanant a tots els meus amics llibres del gran mestre (p. 50).

Desde 1962 fue lo que algunos hicimos.

\section{Nuestro encuentro en la Unión Soviética (julio-agosto de 1962)}

El propio Salvat lo ha contado en un trabajo en el que evocaba nuestra relación durante 37 años:

Conocí a Xesús Alonso Montero en 1962, en Moscú, en un magno Congreso Mundial de la Paz, o sea, del llamado World Peace Council (W. P. C.). Por tanto, hace 37 años que le conozco y, a lo largo de estos años, he estado en contacto con él en momentos tan difíciles como apasionantes, como lo fue, por ejemplo el encuentro en la URSS (p. 903)².

Fue un encuentro clandestino. Sabido es que en la Dictadura de Franco el pasaporte español era «válido para todos los países del mundo excepto Rusia y países satélites». En Moscú también conocí a José Agustín Goytisolo y a Marcos Ana, comunista que había estado en prisión 23 años (1939-1961). Yo era militante del Partido desde hacía dos meses y medio, pero Goytisolo y Salvat no militaban, eran «compañeros de viaje». Hablamos mucho (de literatura y política) durante el Congreso que inauguró Kruschev con un largo discurso, y seguimos hablando en nuestros viajes a Leningrado y a Kiev. Fue aquí donde visitamos al poeta ucraniano Nicolai Bajan, al que Salvat y yo interrogamos minuciosamen-

2 «Momentos compartidos del largo trayecto de X.A.M.», en Cinguidos por unha arela común/Homenaxe ó profesor X.A.M., Universidade de Santiago de Compostela, 1999, vol. I, pp. 903-16. 
te sobre las literaturas no rusas de la Unión Soviética. Allí, según Salvat, se seló nuestra amistad.

Salvat congenió con Enrique Líster, a la sazón presidente de la Delegación española en el Congreso de la Paz; congenió tanto que, sin ser militante del Partido, colaboró con él, en estas actividades, antes y después de la muerte de Franco.

\section{Primer asedio de Salvat a Castelao: 1966}

Entre las grandes obras de nuestro amigo es de justicia destacar el libro en dos volúmenes El teatre contemporani (Barcelona, edicions 62, 1966), una panorámica del teatro mundial inexistente, entonces, en ninguna lengua de la Península. En el volumen II figura, por primera vez en un estudio de estas características, un capítulo dedicado al teatro gallego (pp. 274-77), centrado en gran parte en el comentario de Os vellos non deben de namorarse, la única obra teatral de Castelao. Basilio Losada transmite a Ramón Piñeiro su impresión en estos términos:

Tamén vexo nun libro recenté - El teatre contemporani, de Ricard Salvatun capítulo dedicado ao teatro galego, concretamente a Castelao. Non sei quen informaría ao tal Salvat. No testo cita a Rabanal e a Alonso Montero: as fontes non poden ser máis diverxentes. Salvat é un experto e prestixioso director teatral, perito en Brecht, de quen leva montadas varias obras, a derradeira La bona persona de Se-Zuan con verdadeiro éxito. A valoración que fai de Os vellos... é excelente, aínda que a súa falta de información —que reconoce- empece a debida perspeitiva do capítulo. Por exemplo de Cunqueiro sólo fai unha cita... (24-1-1967)

En ese capítulo Salvat se refiere a mí con estas palabras:

Ens diu l'escriptor gallec X.A.M. que l'obra de Castelao és profundamente gallega i que la seva visió de Galicia posà sempre en relleu la Galícia miserable i soferta, enfront del «señoritismo», que detestava [...] L'interès per la terra gallega va en Castelao unit al seu interés social pel seu poble, canda cap més realista i compromès amb la seva terra i els seus homes... (p. 276).

Quizás tiene en cuenta al escribir este párrafo mi prólogo a la primera reedición de Retrincos (Lugo, Celta, 1962).

Por carta de Basilio Losada a Piñeiro (29-5-1966) sé que Salvat envió su adhesión al magno homenaje tributado en Ourense a Celso Emilio Ferreiro el 15 de mayo de ese año, y con él, Pere Quart, Salvador Espriu, Maria Aurelia Capmany... (p. 524). Confieso que, aun siendo uno de los organizadores de aquel acto, no recuerdo se leyesen en el banquete estas adhesiones.

${ }^{3}$ Do sentimento á conciencia de Galicia/Correspondencia (1961-1984), Vigo, Galaxia, 2002, p. 559 . 


\section{Salvat y yo en una edición polilingüe (tetralingüe): 1968.}

En ese año el poeta vasco Gabriel Aresti (1933-1975) publicó 14 fábulas de Tomás Meabe (Bilbao, 1880-Madrid, 1915) no sólo en la lengua literaria del escritor sino también en euskera (traducción del propio Aresti) en gallego (traducción mía) y en catalán (traducción de R. S.). El volumen, ilustrado por Dionisio Blanco, pertenecía a la editorial Kriselu (Bilbao), que dirigía y gestionaba el poeta vasco, a la sazón muy celebrado por su libro Harri eta Herri (Piedra y Pueblo).

Desde mi punto de vista, de lo que se trataba era de hacer ver a los «curiosos lectores» que en España existían cuatro idiomas literarios, conocido lo cual, algunos, los más exigentes, sugerirían donde fuese que los tres idiomas no oficiales deberían ser sujetos de derechos. A partir de esta fecha (1968), Salvat colaborará en varias empresas tetralingües, coordinadas en Galicia por mí (también Aresti).

\section{Nuevo asedio a Castelao: Salvat, mártir del teatro gallego en el Portugal salazarista (1969)}

A fines de 1968, Salvat fue contratado para dirigir una representación teatral por el Círculo de Iniciação Teatral da Academia de Coimbra (CITAC), lo que lo vinculó muy estrechamente a algunos estudiantes de aquella universidad, entusiastas de la causa teatral y, también de la causa democrática, entusiasmo muy vigilado, entonces, por la policía de Marcelo Caetano, digno sucesor de Oliveira Salazar. Con algunos de estos universitarios portugueses me visitó en Lugo para que los «asesorase» en Castelao por si montaban $O s$ vellos. Tuvimos una larga discusión sobre si debería ofrecerse en versión portuguesa o en gallego, mi punto de vista en principio. Pasado algún tiempo, Salvat optó por realizar un tipo de espectáculo en el que era un maestro desde que había montado uno sobre Adrià Gual y su tiempo. No tardó en ensayar, con los universitarios de Coimbra, el espectáculo Castelao e a súa época, espectáculo que contenía textos del escritor gallego (especialmente de $O s$ vellos) y textos, también en portugués, de otros autores gallegos. En carta del 28 de diciembre de 1969 me comunicaba, al respecto, estos datos:

- La traducción se hizo en colectivo (C.I.T.A.C.). Los poemas más difíciles los tradujeron Niza y Manuel Simoes.

- La música era de JoséNiza Méndes.

- Se cantaban: «Negra sombra» (Rosalía). «Cuando no silencio das noites de luar» (Curros?)

— «Adeus ríos, adeus fontes»

- Las poesías sociales y populares que tú mandaste. Ej.: «Adeus, adeus minha querida, vou partir, vou embarcar». 7 u 8 quartetas.

— «Este parte, aquele parte» (Rosalia)

— «Madrigal á cidade de Santiago» (Lorca). 
- Popular cubana (recogida vía oral por un servidor).

- 2 cuplets de Salvador Espriu y un servidor.

- 1 canción de guerra de Espriu y un servidor.

— «Canção do rapaz da loja» (Lorca).

- Canciones. De Os vellos un total de unas doce canciones.

- En la parte plástica colaboraron João Botelho, el arquitecto que tú conociste - no me puedo acordar del nombre-y, claro está, Seoane. Realizaron los antes mencionados con alumnos de la Escuela de Bellas Artes.

Puesto que nunca se publicó esta obra, considero importante reproducir esta carta de Salvat con indicaciones sobre el contenido de la misma. Debo aclarar que, por lo que recuerdo de la obra, son indicaciones algo incompletas. Me consta que Salvat utilizó bastantes textos de un clásico popular gallego: el Catecismo do labrego (1888). En cuanto a las canciones populares «que tú me mandaste», se refiere al opúsculo Cantigas sociales recollidas do pobo, Col. O Moucho, febrero, 1969 (ed., pról. e notas de X.A.M.).

Fue Alberto Míguez (procesado «por culpa» de Castelao) ${ }^{4}$ quien puso en contacto a Salvat con dos artistas plásticos no ajenos al teatro, Luis Seoane e Isaac Díaz pardo, quienes se encargaron de la escenografía y de los figurines de la obra. El propio Salvat ha contado esta colaboración en un importante artículo: «De cómo dos pintores gallegos me ayudaron a encontrar un camino» ${ }^{5}$.

Estaba previsto que Castelao e a súa época se estrenase en la Universidad de Coimbra el 18 de mayo de 1969, pero la obra no sólo fue prohibida sino que ese día, a las «set del matí, set membres de la PIDE van venir a la meva casa... i mi obligaren a acompañar-los fins la frontera española, om em deixarem», con lo puesto - añado yo - a él, a Nuria Galobardes, su esposa, y a Núria, la hija de dos años. Este y otros episodios, algunos policíacos, son relatados por Salvat en el trabajo «La meva escenificació d'Os vellos non deben de namorarse, d'Alfonso R. Castelao», recogido en su libro Els meus muntatges teatrals (1971).

Debo añadir que el día anterior (el 17 de mayo) yo pronuncié en la Universidad de Coimbra una «Introducción a Castelao» que los organizadores consideraban indispensable - o muy conveniente - para los universitarios conimbrigenses. Pese a que la Universidad estaba totalmente cercada por los policías de uniforme, muchos de ellos con perros que me parecieron feroces, asistieron a mi conferencia centenares de estudiantes. Salvat calificó mi intervención sobre Castelao y la cultura gallega de «admirable». Debo aclarar que él no estuvo entre los asistentes, pues, a esa hora de la tarde, se encontraba en Lisboa, con algunos de los responsables de la actividad teatral, mendigando ante las autoridades educativas unas partículas de libertad para su trabajo. Fue inútil. Unas horas

\footnotetext{
${ }^{4}$ Fue condenado por el Tribunal de Orden Público por el hecho de publicar una antología de textos con este título: El pensamiento político de Castelao. Fue editado, en París, por la editorial Ruedo Ibérico, especialmente odiada por Fraga Iribarne, Ministro de información y Turismo en estas fechas. A Míguez lo defendió el abogado y escritor gallegoValentín Paz Andrade.

${ }^{5}$ La Voz de Galicia, A Coruña, 11-2-1972.
} 
después, casi con nocturnidad, la policía política portuguesa expulsaba abruptamente del país a la familia Salvat.

\section{Lope de Vega relaciona en Barcelona a Salvat con Eduardo Blanco-Amor: 1970-1971}

En una carta de Basilio Losada a Ramón Piñeiro (26-3-1971) leemos:

Tamén hoxe o Blanco-Amor incorporado ao equipo de Ricard Salvat —e ao Teatro Nacional de Barcelona - estrena unha adaptación de El caballero de Olmedo. Pódelle dar algún cartos. Sei que andaba un pouco escorado económicamente. Eu presenteille a Salvat e ligaron ben, no senso profesional - claroe poden facer boas cousas (p. 851)

Me consta que Salvat, muy consciente de la precariedad económica de Blanco-Amor, no sólo remuneró su trabajo de ayudante en la dramaturgia de la obra sino que le proporcionó techo gratuito meses y meses. Poco antes, Salvat tituló una entrevista «Las maravillosas Farsas para títeres de Eduardo BlancoAmor», título que tenía que agradar, forzosamente, a quien nunca había sido considerado un gran autor teatral por la crítica ${ }^{6}$.

\section{Salvat en Lugo: Salvador Espriu y Castelao}

En mayo de 1970, Ricard Salvat viajó a Lugo, invitado por el Club Cultural Valle-Inclán, para hablar de teatro. Finalizada la conferencia, un grupo de amigos de Salvat y algunos directivos del Club redactamos una carta a Salvador Espriu felicitándolo, efusivamente, por el Premio Montaigne que acababa de concederle la Fundación Hamburgo. Espriu, siempre tan exquisito, nos contestó con una carta digna de exhumarse, y yo lo he hecho en un artículo mío publicado en la revista de su Centre de Documentació y Estudi ${ }^{7}$. En ella emite esta opinión sobre nuestro amigo: «Saludin de part meva a Ricard Salvat: és un home tan important com excel-lent».

Recuérdese que la dramaturgia de Salvat estaba al servicio de la obra literaria de Espriu desde 1965, fecha en la que estrenó el espectáculo Ronda de mort a Sinera. Fue Salvat quien, desde hacía algún tiempo, estaba solicitando, una y otra vez de Espriu, que tradujese al catalán Os vellos, de Castelao. En la carta citada (23-6-1970) nos puntualiza:

Traduiré Os vellos..., però els prego que tinguin paciencia. Estic molt condicionat per l'excessiu treball y per la meva mala salut.

\footnotetext{
${ }^{6}$ Tele-Exprés, Barcelona, 29-12-1970.

7 «Mi relación intelectual con S. E.», Indesinenter/Anuari Espriu, Arenys de Mar, n. ${ }^{\circ} 2$, 2007, pp. 89-90.
} 
La conferencia de Salvat, sobre «El teatro, barómetro cultural de los pueblos», fue reseñada en la edición luguesa de La Voz de Galicia, reseña a la que acompaña una foto en la que aparecemos, en el café del Centro (Lugo), el conferenciante, el pintor Luis G. Pacios, mis dos hijos varones (Emilio y Jesús) y yo.

Salvat volvió a Lugo, como conferenciante, en 1972, y también en esa ocasión le enviamos una carta colectiva a Espriu, que él contestó y en la que se despidió con «una fraternal abraçada» $(9-9-1972)^{8}$.

\section{Con Valle-Inclán e Isaac Díaz pardo en Barcelona: 1972}

El 23 de junio de este año Salvat estrena, con la Compañía Nacional Ángel Guimerá, dos piezas de Valle: Ligazón y El Embrujado. Contó, como escenógrafo y figurinista, una vez más con la colaboración de Isaac Díaz Pardo, especialmente valiosa —opino- en la segunda pieza, que «es una tragedia de tierras del Salnés». Díaz Pardo llevó a la plástica de la obra el «humus» gallego de las personas y las cosas, como otrora (en 1933) hizo el artista plástico Castelao en el estreno (Madrid) de Divinas palabras.

En 1972 asiste en el Centro Gallego de Barcelona a una conferencia de Xosé Neira Vilas que le pareció «una persona de alta categoría a todos los niveles». En la misma carta me comunica esta sorprendente noticia:

Estoy viajando mucho en estos últimos tiempos. Estuve en la Sorbona en las «Jornadas Internacionales Universitarias sobre Teatro Gallego». Como no había nadie de Galicia, yo hice una amplia información sobre lo que estáis realizando y sobre el teatro gallego en general. Creo que quedó bien (15-12-1972).

\section{En el Jurado del Primer Certamen de Teatro gallego (Ribadavia, mayo, 1973)}

Ya es un tópico afirmar que Ribadavia (Ourense) fue la capital del teatro gallego, desde este año, durante mucho tiempo, no sólo por la actividad teatral (representaciones y debates) protagonizada por muchos y muy distintos grupos («Mostras de teatro») sino por el certamen de textos teatrales, que tanto contribuyeron a descubrir o consolidar autores. Existe una magnífica monografía sobre esta actividad teatral promovida por la Asociación Cultural «Abrente»: Un abrente cultural. As Mostras e o Concurso de Teatro de Ribadavia (Galaxia, 2002). Sus autoras, Inma López Silva y Dolores Vilavedra, inician el capítulo dedicado al certamen de textos con estas palabras.

... o único requisito esixido polas bases do Concurso era que os textos, ademais de seren inéditos, estivesen en galego. O xurado estivo composto por: Xesús Alonso Montero, o profesor catalán de historia do teatro Ricard Salvat, o dramaturgo Manuel Lourenzo, Xesús Sánchez Orriols «Chucho» —mecenas

${ }^{8}$ Op. cit., pp. $90-91$ 
de Abrente e promotor incansable da vida cultural ribadaviense-e Rodolfo López Veiga (o histórico director da agrupación coral e teatral santiaguesa Cantigas e Agarimos), quen estaba convidado pero non puido asistir (p. 145).

Supongo que fue Sánchez Orriols, que poseía una espléndida biblioteca teatral, quien sugirió el nombre de Ricard Salvat, consciente de la relevancia de su personalidad y del prestigio que le conferiría al jurado y a la aventura teatral que se inauguraba. La experiencia ribadaviense del 16 de mayo de 1973 (víspera del Día das Letras Galegas), fecha del fallo del Jurado, relacionó, aún más, a Ricard Salvat con el teatro gallego y sus autores. En cualquier caso, es significativo que un hombre de teatro extra-gallego estuviese presente en la primera actividad del acontecer ribadaviense, clave, sin duda, en la historia del teatro gallego contemporáneo.

\section{1974: «annus mirabilis» en la biografía gallega de Ricard Salvat}

En mayo de este año, publiqué, en la colección Arealonga, que yo dirigía (en Akal Editor, Madrid), el volumen Encuesta mundial sobre la lengua y cultura gallegas y otras áreas conflictivas: Cataluña, Puerto Rico, etc, volumen que recoge las consideraciones, suscitadas por un cuestionario mio, de 36 intelectuales extragallegos, entre ellos, José Luis Abellán, Margot Arce, Carlos Barral, Castilla del Pino, Salvador Espriu, Guy Heraud, Anne Marie Morris, Manuel Sanchís Guarner, Alfonso Sastre, Hans Schneider, Antonio Tovar y Francesc Vallverdú. Son admirables las seis páginas de Salvat en las que habla de intelectuales y de cuestiones que conocía muy bien: de Pasolini, de Fanon, de la alta burguesía gallega... De Castelao (¡siempre Castelao!) nos dice.

... fue el intelectual gallego, y aún diría más, el intelectual español que se adelantó una generación a su época. El fue el primero que comprendió que había que eliminar el vacío existente entre la cultura burguesa y el pueblo. Mi admiración por él es tan grande que creo que su camino, junto al de Machado y Valle-Inclán, son los más ricos, estéticamente y éticamente, de todos los países de Iberia9.

En el verano de 1974 asistí a la Universitat d'Estiu en Prada, foro que, por estar en territorio francés, permitía una libertad de expresión muy superior a la existente en los foros análogos de España. Mi conferencia sobre el compromiso de Castelao la presentó Salvat, quien dirigió, con su pericia habitual, el animado coloquio posterior. Recuerdo muy bien que, un día después, fuimos a Perpiñán para ver la película más codiciada por las gentes hispanas con alguna inquietud cultural (y erótica): El último tango en París, protagonizada por Marlon Brando y María Schneider. Al regreso, Núria, la esposa de Ricard, nos hizo una foto en la tumba de Pompeu Fabra, en Prada de Conflent, donde el ilustre lingüista falleció en 1948.

${ }^{9}$ De la Encuesta hay edición facsímil, con un nuevo prólogo (mío también), de Alvarellos Editora (Santiago, 2008) 
Por las mismas fechas (julio de 1974) la editorial Júcar (Madrid) editó el álbum Nós, de Castelao, edición que yo prologué y coordiné. En esta edición los pies en gallego de las cincuenta estampas aparecen también en las otras tres lenguas españolas: en castellano (traducción de Antonio Buero Vallejo), euskera (Gabriel Aresti) y catalán (Ricard Salvat).

Algo después (octubre de 1974) publiqué un importantísimo texto gallego en edición tetralingüe: los Seis poemas galegos (1935) de Federico García Lorca. Era el número 1 de la colección «de libros rojos» Arealonguiña, que yo dirigía, como Arealonga, en Akal Editor (Madrid). Colaboran de nuevo Aresti y Salvat; la traducción castellana fue del gran escritor lugués Ánxel Fole.

Salvat, en su día, me comunicó en carta ${ }^{10}$ que, hecha la traducción catalana de los Seis poemas galegos, sometió su versión al criterio de su amiga Marta Pessarrodona, escritora muy considerada en las Letras catalanas en el campo de la creación poética y en el de la traducción.

En cuanto al poema 5..$^{\circ}$ «Cançó de bressol per a Rosalía Castro, morta», se reproduce en un volumen muy posterior: Manuel Curros Enríquez e Federico García Lorca cantan en vinte linguas a Rosalía de Castro/Manuel Curros Enríquez et Federico García Lorca Rosaliam de Castro viginti linguis celebrant, Patronato Rosalía de Castro, 1994.

Debo aclarar que antes de 1974 yo insté a Salvat a que tradujese un texto al catalán. Fue en 1971, y se trataba de un texto en castellano que los organizadores de una exposición filológica queríamos mostrar, en un panel, en las cinco lenguas de la Península ibérica: gallego (Ánxel Fole), catalán (R. Salvat), euskera (Juan San Martín) y portugués (Pilar Vázquez Cuesta). El texto, muy breve, era un texto cervantino: las palabras proferidas por Sancho Panza cuando dimite como gobernador de la Insula Barataria:

... desnudo nací, desnudo me hallo, ni pierdo ni gano, quiero decir, que sin blanca entré en este gobierno, y sin ella salgo, bien al revés de cómo suelen salir los gobernadores de otras ínsulas (Quijote, II, 53).

En la traducción de Salvat reza:

... vaig néixer nu, nu em trobo, ni perdo ni guanyo res; vull dir, que sense un clau vaig entrar en aquest govern, i sense un clau en surto, ben a l'inrevés de com solen sortir-ne els governadors d'altres illes... ${ }^{11}$

A finales de 1974, Luís Seoane dibujó la «figuración» que publicó, semanas después, en su sección de La Voz de Galicia (2-2-1975). En el texto, donde lo

${ }^{10}$ Siento no reproducir el párrafo pertinente: la carta no aparece, entre mis papeles, en la carpeta oportuna.

${ }^{11}$ La versión catalana (con las otras cuatro) figuraba en el correspondiente panel de la Muestra y también en el folleto Exposición de Lingüística hispánica, Instituto Masculino de Lugo, 1971. En diciembre de este año felicité el nuevo año con un tarjetón que contenía el texto cervantino en los cuatro idiomas de España. 
considera «un dos máis importantes direitores teatrais da Peninsua», nos ofrece una información que contradice, en parte, la que hemos ofrecido en el apartado V:

Foi Director do Teatro Universitario de Coimbra, onde ensaiou a representación dunha obra súa, Castelao e a súa época e Os vellos non deben de namorarse, con decorados, figurís, caretas e afiche meus, que por razón políticas non puido entón ser representada públicamente.

En el catálogo Ricard Salvat e la seva época (Ajuntament de Barcelona, 2004 , p. 87) la ficha técnica consigna que la escenografía y el figurinismo había sido obra de Seoane y Díaz Pardo.

\section{En el auditorio de Sargadelos, Salvat ofrece un estreno mundial: 1980}

Ricard Salvat sigue muy vinculado a Isaac Díaz Pardo, que acaba de ofrecerle el auditorio de Sargadelos, que era, en aquellos años, no sólo un escenario de propuestas cerámicas (lo esperable de quien dirigía la emblemática fábrica) sino también el escenario de importantes propuestas literarias, artísticas, teatrales. En el auditorio, la actriz Carla Cristi nos ofreció el monólogo (sin palabras) Música només para vosté, del dramaturgo alemán Frenz-Xaver Kroetz, que montó y dirigió Salvat. Para mí esa experiencia teatral fue extraordinaria. La conté en mi sección del Faro de Vigo con el título «6 de agosto de 1980: a noite na que Carla Cristi se suicidou en Sargadelos» (15-8-1980).

Días antes había publicado en el mismo periódico «Ricard Salvat na «universidade de verán» de Sargadelos» (1-8-1980) ${ }^{12}$, título nada improcedente para quienes conocen la actividad cultural de Sargadelos, en aquellos años, en el mes de agosto. En esos días se habló de teatro y no poco: Salvat, Díaz Pardo, Manuel Lourenzo, Carmen Beltrán, yo... Ya no estaba en estos coloquios con su inmenso saber y su entusiasmo, Luís Seoane, fallecido el año anterior.

En estos años, Salvat dirigió el Festival Internacional de Teatre de Sitges, Festival que acogió con entusiasmo a no pocos grupos gallegos. En la edición de 1979 Salvat, tan atento al acontecer literario gallego, organizó un homenaje al poeta Celso E. Ferreiro, poco después de su fallecimiento.

\section{Salvat traduce la «opera omnia» del poeta medieval Martín Códax: 1983}

A finales de este año el Colegio Universitario de Vigo, donde yo era profesor de Literatura española, publicó un Homenaxe a Martín Códax que difería, notablemente, de otros homenajes tributados al gran poeta vigués del siglo XIII. Martín Códax, autor de siete «cantigas de amigo» que constituyen una especie de breve novela de amor, se ofrecía, en este volumen, en ocho idiomas: caste-

12 Ambos artículos los reproduje en mi libro Escritores: desterrados, namorados, desacougantes, desacougados..., Ediciós do Castro, 1981, pp. 349-57 
llano, gallego moderno, catalán, euskera, francés, italiano, inglés y alemán. Fue Salvat el traductor catalán, traducción que le planteó algunos problemas. En carta me comunicó:

Aquí va la traducción que no me ha sido nada fácil. Como verás, el número 6 lo he dejado en la versión del narrador. Si tú crees oportuno añadir el «yo» como has hecho en castellano, en tus manos lo dejo, aunque a mí me gusta más el tono ambiguo que posee el original. Respecto al quinto, que ha sido para mí el más difícil, he dado una lectura quizá más malintencionada de la que das en la versión castellana. De todas formas, si crees que me he permitido demasiadas libertades, llámame y lo comentamos (2-11-1983).

No lo llamé. En cuanto a la versión castellana por él citada, no es mía, mejor dicho, no lo es en su totalidad. La elaboré, en varios «seminarios», con cuatro alumnos de tercer curso de Filología: Xosé M. Fernández González, Marisol Fernández Montoto, Xosé Troitiño Fraiz y Cristina Velasco Toepfer. A partir de este trabajo, los dos primeros realizaron la versión inglesa, Xosé Troitiño la francesa, y Cristina Velasco la alemana.

El volumen contenía también varios trabajos críticos y algunas notas eruditas de especialistas en lírica medieval gallego-portuguesa (Arcadio López-Casanova, Martín de Riquer...). Ricard Salvat estaba muy orgulloso de su colaboración, consciente de que, con su versión, contribuía a la difusión, por tierras de lengua catalana, de una de las voces más importantes y turbadoras del Parnaso medieval europeo.

\section{De nuevo, Castelao: Vigo, 1986}

Era el centenario del nacimiento del gran escritor, yo organicé un ciclo de conferencias en la Caja de Ahorros y entendí que no podía estar ausente la voz sabia y comprometida de Ricard Salvat. El 4 de abril de ese año nos ofreció una lección más: «La única obra teatral de Castelao». Se recoge en catalán en el volumen ya mencionado, Escrits per al teatre (pp. 103-111).

Cita en la conferencia más de una vez a Manuel Lourenzo con quien, en no pocas ocasiones, conversó sobre el teatro gallego.

\section{Salvat y Bertolt Brecht en el Museo «Carlos Maside» (O Castro de Osedo, A Coruña): 1988}

Con el fondo documental e iconográfico del propio Salvat, tan rico en fotografías, carteles y documentos sobre Brecht y su teatro, el Museo «Carlos Maside» ofreció una exposición con ocasión del nonagésimo aniversario del nacimiento del gran dramaturgo alemán. Por esos días, Ediciós do Castro, dirigida por Isaac Díaz Pardo, publicó un libro de Salvat con el título Bertolt Brecht no 90 aniversario do seu nascimento, volumen que recoge trabajos y artículos de nuestro amigo dados a conocer entre 1956 y 1988. En el prólogo, Díaz Pardo resalta que Salvat «foi tamén o introductor do coñecemento de Brecht na España». 
Que fue un pionero lo demuestra el primer trabajo del libro, «A manera de introducción a B. B. y su revolucionaria manera de entender el hecho teatral», conferencia leída, a fines de 1956, como trabajo de curso, en la cátedra de Estética del profesor José M. ${ }^{a}$ Valverde (Universidad de Barcelona).

Se trata, sin duda, de un homenaje al revolucionario dramaturgo alemán, pero, para aquellos que conocemos a Isaac Díaz Pardo, es también un homenaje a Ricard Salvat, a una de las grandes dimensiones del hombre de teatro que fue Ricard Salvat: la de quien introdujo y consolidó la obra teatral de Brecht en España. Galicia, de la mano de Díaz Pardo, se adelantaba a la misma Cataluña, tan parca en reconocimientos a quien llevó el nombre del teatro catalán a foros y escenarios de Europa y América muy relevantes.

\section{Palabras de Ricard Salvat para Isaac Díaz Pardo: 1990}

El Ayuntamiento de Santiago ideó y realizó el primer gran reconocimiento que Galicia hizo a Díaz Pardo, reconocimiento que cristalizó en un monumental volumen titulado Isaac Díaz Pardo/Un proxecto socio-cultural para Galicia (1990). Prologa el volumen Xerardo Estévez, arquitecto y alcalde de Compostela, en realidad el padre de la idea. Entre los 19 colaboradores figura quien no podía estar ausente: Ricard Salvat. Su trabajo «Aproximación a Isaac Díaz Pardo», son unas páginas, en buena parte, autobiográficas. Son las páginas de quien evoca, agradecido, los encuentros con Díaz Pardo, algunos de los cuales fueron tan fructíferos para la definición y difusión de Castelao y Valle-Inclán. Como sucede en las páginas de otros colaboradores, no omite Salvat, al referirse a Díaz Pardo, su condición cívica. «Esta, su lección de civismo unida a sus infinitas aportaciones estéticas, convierte a Isaac en una de las personalidades más fascinantes, originales y arriesgadas no ya de Galicia sino de toda la Península ibérica».

\section{La gran cita de Salvat con Álvaro Cunqueiro: 1991}

En setiembre de este año, Mondoñedo, su ciudad natal, acogió un magno Congreso cuyas actas publicó, dos años después, la Xunta de Galicia con el título Congreso Álvaro Cunqueiro. El volumen recoge la disertación de Salvat, «Cunqueiro y el teatro europeo de su tiempo», pronunciada el día 12 en una sesión en la que yo presenté al conferenciante. Debemos precisar que el mismo texto, y con el mismo título, fue publicado dos años antes en el número 241 de Primer Acto (noviembre-diciembre de 1991), revista que, bajo la dirección de José Monleón, siempre estuvo muy atenta al acontecer teatral gallego, incluso antes de la muerte de Franco. El número, en buena parte dedicado al teatro de Cunqueiro $^{13}$, también ofrece, en traducción castellana de Xosé Cermeño, $O$ incerto señor don Hamlet, la obra más importante del dramaturgo gallego.

${ }^{13}$ Contiene trabajos, además del de Salvat, de Helena González, Dolores Vilavedra, X. Alonso Montero, Manuel Lourenzo, X. Cermeño, José Monleón, Damián Villalaín y del propio Cunqueiro. 
En setiembre de 1991, Salvat ya había sido contratado por el Centro Dramático Galego (Santiago), dirigido por el profesor Luís Cochón Touriño, para montar el peculiar Hamlet de Cunqueiro. Se estrenó con éxito en Compostela el 18 de octubre de ese año, y éxito obtuvo la representación en otras localidades de Galicia. De la bibliografía suscitada por Salvat como director de O incerto señor don Hamlet, yo destacaría el artículo del crítico teatral Damián Villalaín, «Ricard Salvat dirige Don Hamlet para el Centro Dramático Galego», publicado en el número citado de Primer Acto (pp. 57-59). Supo extraer de la obra —opina Villalaín— «todo su potencial espectacular» devolviendo a Cunqueiro «categoría de escritor teatral, de dramaturgo eficaz no sólo en el texto sino también en los escenarios».

\section{En Barcelona, con el escritor «gallego» Carles Riba: 1993}

Era este el año del centenario del nacimiento del gran poeta y traductor catalán Carles Riba (1893-1959), autor, en su juventud, de dos poemarios en lengua gallega dedicados a una «noia» barcelonesa hija de gallegos. Fue su musa y por ella aprendió el gallego (y no mal), y en gallego escribió los poemarios, inéditos hasta 1987. Por sus versos gallegos le tributamos un homenaje en la Facultad de Filología de Santiago en abril de 1993, fecha en la que la editorial Galaxia (Vigo) publicó un volumen, prologado y coordinado por mí, con el título Carles Riba e Galicia. En él, además de ofrecer la edición cuidada de los poemarios gallegos, se ofrecía la biobibliografía completa de Riba: artículos, cartas, traducción catalana de los versos gallegos, noticias sobre su viaje a Galicia con motivo del III Congreso de Poesía... Salvat consideró tan importante el volumen que decidió presentarlo, con no poca solemnidad, en su Facultad de Barcelona, donde él desempeñaba la cátedra de Historia del teatro catalán. Nuestro gran amigo nos ha dejado esta versión del acto.

Alonso Montero quiso que el libro se presentara en el marco de nuestras clases de la Universidad y no en ninguno de los sitios habituales, usados para estos menesteres, por el Partido en el Poder. Según su elegante proceder fue un emotivo homenaje a nuestra labor en pro del diálogo Galicia-Catalunya durante tantos años. Puente de Diálogo del que ahora nadie parece querer acordarse, pero él sí. Y esta decisión suya fue muy reveladora, y la agradecemos ${ }^{14}$.

\section{Salvat en Budapest y en Santiago: 1994}

A primeros de febrero de 1994, Salvat estrenó en el Teatro Nacional de Budapest Az ember tragédiája (La tragedia del hombre) del dramaturgo Imre Madách (1823-1864), obra cuyo montaje siempre ha planteado grandes problemas. Contaba Salvat, para los aspectos plásticos, con el concurso de Isaac Díaz Pardo, colaboración que se limitó a diseñar unas ideas que realizó, «in situ», Xosé Vizoso, no ajeno a los criterios de Díaz Pardo por trabajar a su lado, como dibujante, en la cerámica de Sargadelos.

${ }^{14}$ Op. cit., en n. 2, pp. 970-71. 
Conozco una reseña de la obra, firmada por José Ollé (Escena, marzo, 1994) donde subrayaba que era muy poco frecuente que un director catalán fuese invitado a dirigir en un Teatro Nacional centroeuropeo; también se lamentaba de que una personalidad como la de Salvat «no estreni amb una certa regularitat a casa nostra».

Meses después de su éxito en Budapest, Salvat volvió a Santiago de Compostela, esta vez para intervenir en el Jurado que concedió el Premio de Teatro Xacobeo en su segunda edición.

\section{Premio «Rosalía de Castro» del PEN Clube de Galicia: 2002}

Cada dos años, esta institución concede ese galardón a cuatro escritores: uno de lengua castellana, otro de lengua vasca, un tercero de lengua catalana y el cuarto de lengua portuguesa. En la edición de 2002 fueron premiados, respectivamente, Ernesto Sábato, Felipe Juaristi, Ricard Salvat y Nélida Piñón. Hay que reconocer que nuestro amigo no iba en mala compañía.

Hay un «precepto» tácito según el cual los premiados deben referirse, en su alocución, aunque sea brevemente, a la obra de Rosalía de Castro, y así lo hicieron los galardonados en el acto solemne de la entrega del Premio, en el Salón Artesonado de Fonseca, el 2 de mayo de 2002. Esos textos rosalianos fueron editados en un opúsculo por el PEN Clube y reproducidos, algo después en la $R e$ vista de Estudios Rosalianos (Padrón, n. ${ }^{\circ}$ 2, pp. 55-74).

En su intervención «A propòsit de Rosalia», Salvat recuerda su primer contacto con nuestra escritora, cuando, alumno de bachillerato en el Instituto de Tortosa, se encontró con su nombre y algunos de sus versos en el libro de texto de Ángel Lacalle, aunque el profesor de la asignatura «ens decía que els apartats de literatura catalana i gallega no calia ni llegar-los». La consecuencia fue que «eren els capítols que llegia amb més interés i dilectació». En su alocución también tuvo un recuerdo para uno de sus trabajos más queridos, Castelao e a súa época (Coimbra, 1969), espectáculo que acogió algunos poemas de Rosalía. Ya aquí, precisa: «El gran músic i poeta José Niza va posar música a aquests poemes i alguns els va després en disc». Doy fe de que algunos versos de rosalía (por lo menos, «Este vaise e aquel vaise») conmovían en la voz y en la música del estudiante de Medicina José Niza, años después diputado en Portugal por el Partido Socialista.

La revista Citania (Artes, Letras y Espectáculos), que dirigía en Santiago el dramaturgo Euloxio R. Ruibal (con la colaboración de M. ${ }^{a}$ Antonia Pérez), aprovechó los días compostelanos de Salvat para hacernos una entrevista a él, a Isaac Díaz Pardo y a mí. Fue una entrevista memorable, guiada con mano sabia por la joven Inma López Silva, hoy ya una autoridad en cuestiones teatrales gallegas y no gallegas. En el número 4 de Citania (primavera/verano, 2003), la joven profesora presenta de este modo a los «tres persoeiros da Cultura»:

Xesús Alonso Montero, Ricard Salvat, Isaac Díaz Pardo. Tres amigos de tempos pasados, que se remontan a días, sen dúbida, máis difíciles. Os tempos cando Díaz Pardo estaba en América, cando Alonso Montero era quizais o mozo 
máis rebelde de cantos se viron e se ven, ou de cando Ricard Salvat corría dun lado a outro do mundo, levando a palabra de Brecht de escenario en escenario, ou soñando tempos de paz en Moscova, 1962... Homes dos tempos en que posuír o don das mentes lúcidas, era un exercicio de rebeldía. Definámolos, parafraseando a Alonso Montero, cun pleonasmo hiperbólico: intelectual de esquerdas.

En el extenso coloquio, muy bien recogido y «editado» por Inma López Silva, se habla del Capitalismo, de la Universidad, de los medios de comunicación, de las nacionalidades históricas y de teatro, tema este en el que resplandecían las palabras de Ricard Salvat. También hablamos de nuestro primer encuentro, en Moscú, en julio de 1962.

\section{Salvat, Enrique Líster, el cine... y final}

En setiembre del 2006 Margarita Ledo, cineasta y profesora de la Facultad de Ciencias de la Información, convocó a varias personas, en Castro de Rei (Lugo), para filmar algunas de las escenas del film Liste, pronunciado Líster, ya estrenado (y que yo todavía no he visto). Entre los convocados estaba Ricard Salvat, muy amigo de Enrique Líster desde 1962 y con el que colaboró, durante varios años, en actividades del Consejo Mundial de la Paz. Me consta que para esta película-documental sobre Líster (Calo, Teo, 1907-Madrid, 1994) se filmaron escenas en París, Moscú, Praga y otros lugares transitados por el dirigente comunista gallego antes y después de la Guerra Civil. La presencia de Salvat en el film constituye la última imagen gallega de nuestro amigo.

El 24 de marzo de 2009, como consecuencia de un derrame cerebral, Ricard Salvat falleció en Barcelona. A las pocas horas, Núria, su hija mayor, nos comunicó noticia tan dolorosa como inesperada a Isaac Díaz Pardo y a mí, que nos encargamos de transmitirla a otros amigos y admiradores gallegos. El Teatro (con mayúscula) estaba de luto, y de un modo muy especial, el teatro gallego.

Esto es lo que intentamos expresar en nuestros artículos necrológicos, al día siguiente, Díaz Pardo, Xosé Neira Vilas, Moncho Ramos Requejo, yo... ${ }^{15}$. Desde entonces, contrajimos el compromiso de tributarle un homenaje a Ricard Salvat, un homenaje que se acerque, en la medida de lo posible, a la grandeza, el talento y la eficacia que puso en todas sus actividades literarias, algunas de las cuales llevaron el nombre de Galicia por lugares insospechados del mapa cultural del mundo.

Conviene tener muy presente, por otra parte, que, con la muerte de Ricard Salvat, desaparece no sólo una de las grandes personalidades del teatro catalán (y español) sino una personalidad relevante de la causa mundial del Teatro. Esto lo saben quienes en Cataluña, en los últimos años, lo hicieron objeto de silencios y

15 Sé que se publicaron otras notas necrológicas en la prensa gallega de esos días. Las mencionadas aparecieron en La Voz de Galicia (25-3-2009), en El Correo Gallego (la de X. N. V.) y en La Región (1-4-09, la de M. R.R.) 
pretericiones, como saben también que el joven Salvat hizo, por la modernidad del teatro y del espectáculo teatral, lo que nadie sabía hacer o se atrevía a llevar a la escena. Eran tiempos muy inhóspitos, en la «pell de brau», para cualquier actividad cultural con pretensiones de impacto en el público. Alrededor de 1960, el joven Salvat impresionaba a los entendidos e inquietaba al Poder porque acababa de situar en el centro de la escena unas palabras y unos modos que los biógrafos del teatro tendrán que examinar con admiración y todos nosotros con gratitud. 
